\title{
Preventive medicine clinics in hospitals of India: An opportunity missed
}

Non-communicable Diseases (NCDs) are emerging as a major cause of morbidity and mortality. Control of risk factors and early diagnosis and treatment are cost-effective modalities for prevention. To attain this, Preventive Medicine Clinics must become a regular feature in the government hospitals of India. Community Medicine and/ or Family Medicine specialists of medical colleges can establish these clinics. In addition to screening patients for NCDs and their risk factors, these clinics can screen patients who require primary health care and manage them appropriately.

Key words: Non-communicable diseases, preventive medicine clinics, primary prevention, risk factors, screening, secondary prevention

Hemant Deepak Shewade, Palanivel Chinnakali

Department of Community Medicine, Indira Gandhi Medical College and Research Institute, A Government of Puducherry Institution, Puducherry, India

Address for the Correspondence: Dr. Hemant D Shewade, Assistant Professor, Department of Community Medicine, Indira Gandhi Medical College and Research Institute (IGMCRI), A Government of Puducherry Institution,

Puducherry - 605 009, India. E-mail: hemantjipmer@gmail.com

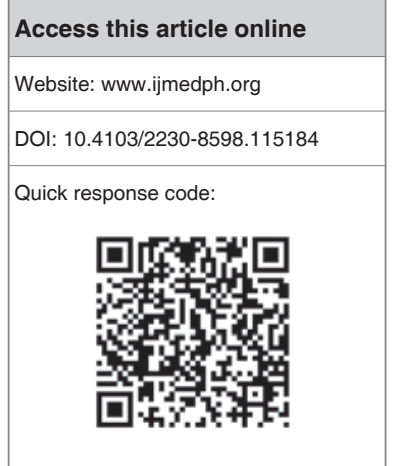

\section{INTRODUCTION}

As a result of epidemiological and demographic transition, Non-communicable Diseases (NCDs) are emerging as the major cause of morbidity and mortality globally. According to a World Health Organization (WHO) report (2002), cardiovascular diseases (CVDs) will be the largest cause of death and disability in India by $2020 .{ }^{[1]}$ The WHO member states have agreed to the goal of ' 25 by 25': Twenty-five percent reduction in mortality due to four main NCDs (CVDs, diabetes, cancer, and chronic respiratory diseases) by 2025. ${ }^{[2]}$ The National Program for Control and Prevention of Cancer, Diabetes, Cardiovascular diseases, and Stroke (NPCDCS) aims to integrate NCDs into the existing framework of the National Rural Health Mission (NRHM). ${ }^{[3]}$

Treatment of NCDs being expensive, the overall cost of treatment has increased. Control of risk factors and early diagnosis and treatment are cost-effective modalities for prevention. ${ }^{[4]}$ Hence, the need for primary and secondary prevention of NCDs at all levels of healthcare. We propose the establishment of preventive medicine clinics at hospitals, especially under medical colleges, to provide these services.

\section{ROLE OF PREVENTIVE MEDICINE CLINICS}

It is a known fact that tertiary hospitals in India are overburdened ${ }^{[5,6]}$ by patients requiring a lower level of expertise, because of the failure of primary and secondary healthcare. In addition, there is no mechanism put in place to check this. In such a scenario, preventive medicine clinics can play a dual role in tertiary hospitals: (i) For opportunistic screening of NCDs and (ii) as screening Outpatient Departments (OPD). As a clinic for opportunistic screening of NCDs, patients can be screened for risk factors for NCDs (primary prevention) like tobacco, alcohol, physical inactivity, diet, and so on, and various $\mathrm{NCD}$ /chronic illnesses (secondary prevention) like diabetes, hypertension, obesity, hypercholesterolemia, cataract, breast cancer, cervical cancer, oral cancer, colorectal cancer, buman immunodeficiency virus (HIV), and the like. The standard screening criteria and screening tests must be used, which will make the whole process cost-effective. Preventive medicine clinics can also act as screening OPDs to filter patients, who require secondary/tertiary care, and refer them to the appropriate OPDs after initiating primary healthcare. Those who require primary care only, can be managed at this level itself. Here too, standard management protocols must be followed. This will reduce the burden on other clinical specialties; which will enable them to give quality care to the patients referred to them by the preventive medicine clinic.

Irrespective of the specialty or super-specialty, a clinician must be trained in preventive medicine, but the reality is different. We have to agree that the preventive medicine component has not been given 
enough emphasis in the medical curricula. ${ }^{[7]}$ Preventive medicine is an integral part of Community Medicine practice. It is part and parcel of the family health practice. Special clinics called Preventive Medicine Clinics must be part of a hospital setup. The concept of preventive medicine clinics has picked up outside India. ${ }^{[8,9]}$ They are not a regular feature of our government hospitals in India; although one can find them in corporate hospitals. ${ }^{[10-12]}$

Hence, clinicians who are trained both in preventive medicine and clinical medicine, say community physicians (public health, preventive and social medicine, community medicine) or family physicians (family medicine) can establish preventive medicine clinics in their respective hospitals and health centers. These clinics may have a faculty in charge and various trained medical and paramedical staff.

\section{REFERENCES}

1. World health Organization. The world health report 2002: Reducing risks, promoting healthy life. Geneva: WHO; 2002. Available from: http://www. who.int/whr/2002/en/whr02_en.pdf. [Last cited on 2012 Oct 18].

2. Lancet NCD action group. Measuring progress on NCDs: One goal and five targets. Lancet 2012;380:1283-5.

3. Directorate general of health services. Ministry of health and family welfare. Govt. of India. National programme for prevention and control of cancer, diabetes, cardiovascular diseases and stroke: Operational guidelines [Internet]. 2010. Available from: Available from: http://health. bih.nic.in/Docs/Guidelines-NPCDCS.pdf. [Last cited on 1012 Oct 18].

4. World Health Organisation. 2008-2013 Action Plan for the Global Strategy for the Prevention and Control of Noncommunicable Diseases [Internet]. 2009. Available from: http://whqlibdoc.who.int/ publications/2009/9789241597418_ eng.pdf. [Last cited on 2012 Oct 24].
5. Upgradeothercityhospitals, saysan 'overburdened'PGI.The IndianExpress [Internet]. 2009 Dec 18. Available from: http://www.indianexpress.com/ news/upgrade-other-city-hospitals-says-an--overburdened--pgi/555643. [Last cited on 2012 Nov 17].

6. Govt. hospitals overburdened. Afternoon [Internet]. 2012 Jul 26. Available from: http://www.afternoondc.in/city-news/govt-hospitals-overburdened/ article 61271. [Last cited on 2012 Nov 17].

7. Talwar K, Grover A, Thakur J. Role of medical education in preventing and control of noncommunicable diseases in India? Indian J Community Med 2011;36:S63-6.

8. Lee M, Entzminger L, Lohsoonthorn V, Williams MA. Risk factors of hypertension and correlates of blood pressure and mean arterial pressure among patients receiving health exams at the Preventive Medicine Clinic, King Chulalongkorn Memorial Hospital, Thailand. J Med Assoc Thai 2006;89:1213-21.

9. Hernández-García I, González-Torga A, Villanueva-Ruiz C, García-Shimizu P, Martín-Ruiz AC, Arnau-Santos M. Satisfaction among patients attending outpatient preventive medicine clinic. Rev Calid Asist 2010;25:83-9.

10. Clinic Rejuvè-Preventive Medicine Programme. Fortis hospital, Mohali [Internet]. 2012. Available from: http://www.fortishealthcare.com/ india/Mohali/content/14_14_80_1/Health-Check-Packages.html. [Last cited on 2012 Nov 17].

11. Preventive care:Apollo hospitals [Internet]. 2012. Available from: http://www. apollohospitals.com/byspecialitylanding. php? pageid=Preventive $\% 20$ Care. [Last cited on 2012 Nov 17].

12. Health check centre and preventive medicine centre. Ruby hall clinic [Internet]. 2012 Available from: http://www.rubyhall.com/content/ health-check-centre-preventive-medicine-centre. [Last cited on 2012 Nov 17]

How to cite this article: Shewade HD, Chinnakali P. Preventive medicine clinics in hospitals of India: An opportunity missed. Int J Med Public Health 2013;3:115-6.

Source of Support: Nil, Conflict of Interest: None declared. 